\title{
OdontoTech: fomento ao ensino e à inovação tecnológica - Relato de experiência de
}

\section{um projeto de ensino}

\author{
OdontoTech teaching project: fostering teaching and technological innovation - Experience report \\ of a teaching project
}

OdontoTech: fomento de la docencia y la innovación tecnológica - Informe de experiencia de un proyecto docente

\author{
Georgia Arla Cabrera Khader \\ ORCID: https://orcid.org/0000-0003-1769-5200 \\ Universidade Federal de Pelotas, Brasil \\ gekhader@hotmail.com \\ Mateus Costa Silveira \\ ORCID: https://orcid.org/0000-0002-5576-9672 \\ Universidade Federal de Pelotas, Brasil \\ E-mail: mateuscs13@hotmail.com \\ Rafael Guerra Lund \\ ORCID: https://orcid.org/0000-0003-1006-3809 \\ Universidade Federal de Pelotas, Brasil \\ E-mail: Rafael.lund@gmail.com
}

\begin{abstract}
Resumo
O projeto de ensino OdontoTech teve como objetivo abordar à inovação tecnológica e o empreendedorismo no curso de odontologia, visto a deficiência na Lei de Diretrizes e Bases da Educação Nacional no âmbito acadêmico. Este projeto buscou capacitar os alunos e qualificá-los para atuar no contexto da economia do conhecimento, como agente articulador e executor de ações que visassem preparar os estudantes universitários para o mercado de trabalho, além de contribuir para o fomento à atividade empresarial e a capacitação da comunidade acadêmica para o empreendedorismo e à inovação. Além disso, o ensino tecnológico ocorre quando universidades se comprometem no desenvolvimento de múltiplas habilidades dos alunos, criando um ambiente de estímulo a processos de inovação. O projeto consistiu em doze encontros quinzenais, com apresentação de minicursos de empreendedorismo e inovação tecnológica, com duração de aproximadamente uma hora e trinta minutos, realizados na Faculdade de Odontologia da UFPel. Os temas abordados seguiram quatro eixos temáticos, sendo eles: "Experiências empreendedoras", "Inovação tecnológica", "Planejamento de modelo de negócios" e "Informação e atualização em empreendedorismo". As ações do projeto contemplaram assessorias e mentorias sobre empreendedorismo e inovação tecnológica, além da realização dos minicursos quinzenais sobre o tema. Os encontros quinzenais buscaram elucidar de forma didática os principais itens que devem ser observados em um negócio, além de propor para os alunos uma metodologia prática por meio da ferramenta Canvas de planejamento estratégico. Este projeto contemplou como ouvintes cerca de duzentos discentes. Dessa forma, esse relato de experiência buscou descrever as ações realizadas pelo projeto e seus impactos no meio acadêmico.
\end{abstract}

Palavras-chave: Ensino superior; Odontologia; Métodos de ensino.

\begin{abstract}
The OdontoTech teaching project aimed to address technological innovation and entrepreneurship in the dentistry course, given the deficiency in the Law of Guidelines and Bases for National Education in the academic sphere. This project sought to train students and qualify them to act in the context of the knowledge economy, as an articulating agent and executor of actions aimed at preparing university students for the labor market, in addition to contributing to the promotion of business activity and training from the academic community to entrepreneurship and innovation. In addition, technological education occurs when universities commit to the development of multiple student skills, creating an environment that encourages innovation processes. The project consisted of twelve fortnightly meetings, with presentation of mini-courses on entrepreneurship and technological innovation, lasting approximately one hour and thirty minutes, held at the Faculty of Dentistry of UFPel. The topics covered followed four thematic axes, namely: "Entrepreneurial experiences", "Technological innovation", "Business model planning" and "Information and updating in entrepreneurship". The project's actions included advice and mentoring on entrepreneurship and technological innovation, in addition to holding biweekly mini-courses on the subject. The fortnightly meetings
\end{abstract}


sought to elucidate in a didactic way the main items that must be observed in a business, in addition to proposing a practical methodology for students through the Canvas tool for strategic planning. This project included approximately two hundred students as listeners. Thus, this experience report sought to describe the actions carried out by the project and their impacts on the academic environment.

Keywords: Higher education; Dentistry; Teaching methods.

\section{Resumen}

El proyecto docente OdontoTech tuvo como objetivo abordar la innovación tecnológica y el emprendimiento en el curso de Odontología, dada la deficiencia de la Ley de Lineamientos y Bases de la Educación Nacional en el ámbito académico. Este proyecto buscó capacitar a los estudiantes y capacitarlos para actuar en el contexto de la economía del conocimiento, como agente articulador y ejecutor de acciones dirigidas a preparar a los estudiantes universitarios para el mercado laboral, además de contribuir a la promoción de la actividad empresarial y la formación desde la comunidad académica al emprendimiento y la innovación. Además, la educación tecnológica se da cuando las universidades se comprometen con el desarrollo de múltiples habilidades de los estudiantes, creando un entorno que incentiva los procesos de innovación. El proyecto consistió en doce encuentros quincenales, con presentación de minicursos sobre emprendimiento e innovación tecnológica, de una hora y media de duración aproximadamente, realizados en la Facultad de Odontología de UFPel. Los temas tratados siguieron cuatro ejes temáticos, a saber: "Experiencias emprendedoras", "Innovación tecnológica", "Planificación del modelo de negocio" e "Información y actualización en emprendimiento". Las acciones del proyecto incluyeron asesoramiento y mentoría sobre emprendimiento e innovación tecnológica, además de la realización quincenal de minicursos sobre el tema. Las reuniones quincenales buscaron dilucidar de forma didáctica los principales puntos que deben observarse en una empresa, además de proponer una metodología práctica para los estudiantes a través de la herramienta Canvas para la planificación estratégica. Este proyecto incluyó aproximadamente a doscientos estudiantes como oyentes. Así, este informe de experiencia buscó describir las acciones realizadas por el proyecto y sus impactos en el entorno académico.

Palabras clave: Educación Superior; Odontología; Métodos de enseñanza.

\section{Introdução}

A entrada em vigor da Lei Federal de Inovação (Lei n. 10.973, de 2 de dezembro de 2004) traz ao meio acadêmico o encargo do desenvolvimento científico e tecnológico por meio da aproximação com o setor empresarial e industrial (Junior \& de Souza Baddauy, 2021). O eixo de sustentação ensino-pesquisa-extensão, no qual as universidades estão inseridas, impõe que a academia não apenas produza conhecimento, mas gere soluções para as problemáticas (Etzkowitz \& Zhou, 2017).

Os conhecimentos sobre inovação, Propriedade Intelectual (PI) e empreendedorismo são essenciais para formar profissionais mais preparados para atuar no cenário da economia do conhecimento (Freire \& de Carvalho, 2021). A necessidade de busca por soluções mais rápidas e acessíveis, com baixo custo de produção e constante aprimoramento de tecnologias são inerentes ao contexto atual, sendo imperativo ao acadêmico desenvolver capacidade de liderança, solução de problemas e inovações tecnológicas (Fragoso, Rocha-Junior \& Xavier, 2020).

Tradicionalmente, as Instituições de Ensino Superior (IES) qualificam os seus alunos para um mercado de trabalho formal, no entanto, com as mudanças constantes na economia e na geração de tecnologias há uma transformação no ensino (Carmona, Martens \& de Freitas, 2020). Atrelado a essas mudanças, percebeu-se a inserção do empreendedorismo nas grades curriculares dos cursos superiores, buscando gerar novas oportunidades no mercado atual de trabalho (de Oliveira, Melo \& de Muylder, 2016).

Em consonância a isso, o projeto de ensino OdontoTech pode ser considerado, de acordo com o Portal institucional da Universidade Federal de Pelotas (UFPel) (2018), como um fomento à ações que tem como objetivo a promoção dos conhecimentos acerca do empreendedorismo e da inovação tecnológica, destinado à alunos de graduação do curso de odontologia da universidade. As ações do projeto contemplaram assessorias e mentorias sobre empreendedorismo e inovação tecnológica, além da realização de minicursos quinzenais sobre o tema. O projeto teve como objetivo instigar e impactar o desenvolvimento acadêmico dos alunos envolvidos a partir dos conhecimentos, por eles adquiridos, a respeito de empreendedorismo e inovação (Portal institucional UFPel, 2018). Além disso, estimular ao empreendedorismo inovador, com 
vistas ao desenvolvimento da propriedade intelectual e à transferência das tecnologias desenvolvidas dentro do ambiente acadêmico.

Com esse projeto de ensino, a prática empreendedora foi abordada como atividade complementar, a qual contribuiu para o fomento da atividade empresarial e a capacitação da comunidade acadêmica para o empreendedorismo e a inovação (Prastyaningtyas, Setjipto \& Rudijanto, 2020). Dessa maneira, o ensino empreendedor, treinamentos e especializações sobre o tema podem permitir o desenvolvimento de múltiplas habilidades nos alunos, criando um ambiente de estímulo à inovação (Kimwolo, Saina \& Cheserek, 2012).

De acordo com Dickson e colaboradores (2008) os alunos que se envolvem em atividades acadêmicas de ensino que abordam o empreendedorismo e a inovação tecnológica durante o curso de graduação se aproximam da realidade do mercado de trabalho e criam uma expectativa mais realista em relação à profissão. Além disso, é evidenciado que há uma maior satisfação com a escolha profissional por parte dos alunos que se envolvem com esses tipos de atividades de cursos, bem como participam de feiras tecnológicas, cursos realizados por outras instituições e estágios (de Oliveira Matos et al., 2019).

Dessa forma, o objetivo desse relato é abordar a experiência do projeto de ensino OdontoTech, buscando elucidar a importância da educação empreendedora e da inovação tecnológica na inserção das atividades de discentes de um curso de graduação em odontologia.

\section{Educação empreendedora}

A literatura relacionada à temática enfatiza a importância do desenvolvimento de competências para uma formação superior de qualidade, pregando que seja respeitada as especificidades de cada área de formação, em pelo menos três classes gerais: a capacidade analítica, a capacidade instrumental e a capacidade social (del Prette, 2003). Isso é, certamente, desenvolvido na prática laboral vivida pelos alunos, sendo que a aprendizagem é o processo que possibilita a aquisição e o aprimoramento das competências (Drejer, 2000).

O desenvolvimento de competências e habilidades do aluno é um dos principais pontos da educação empreendedora e capaz de promover uma mudança no sistema educacional (Kirby, 2007). Essas qualidades podem estar intimamente ligadas a ações, pensamentos e vivências as quais auxiliam na construção de uma atitude empreendedora (Lackéus, 2016).

As Diretrizes Curriculares Nacionais (DCNs) do curso de Odontologia foram instituídas no ano de 2002 e servem para padronizar as IES do país quanto ao ensino. No dia 21 de junho de 2021, o MEC publicou uma atualização dessas normas, que começou a valer a partir do dia $1^{\circ}$ de julho (Brasil, 2021). Foi estabelecido que a graduação em odontologia deverá ser generalista de forma que inclua o desenvolvimento de capacidades de liderança e de gestão. Dessa forma, a aquisição de conhecimentos referentes à liderança, gestão, administração e empreendedorismo justifica a inclusão desses assuntos na grade curricular dos cursos de Odontologia. No mesmo sentido, os profissionais de saúde deverão ter a capacidade de tomada de decisões de forma eficaz e objetivando o bem estar dos pacientes, além de serem pró-ativos, gerenciar funcionários e recursos materiais e financeiros (Uliana, 2015).

$\mathrm{Na}$ área educacional, foi incorporado às grades curriculares das instituições de ensino superior (IES) no Brasil primeiramente por meio das Diretrizes Curriculares Nacionais do Curso de Graduação em Administração (Saraiva, 2007). O empreendedorismo foi introduzido pela primeira vez em no início da década de 1980 pela Fundação Getulio Vargas, como disciplina do curso de especialização em Administração. Concomitantemente a isso, as instituições passaram a incentivar o desenvolvimento de empresas juniores em diversos cursos de graduação e projetos não obrigatórios que abordassem o assunto, adquirindo relevância e incorporando junto às incubadoras de empresas por aproximação, alinhamento e adequação entre práticas acadêmicas e práticas de mercado (Dionello, Langhi \& Okano, 2020). 
No entanto, empreendedorismo é ainda pouco debatido na maioria das instituições de ensino superior. Há um trabalho efetivo nas universidades por meio de um conjunto de ações relacionadas à inovação e à criação de competências necessárias ao empreendedorismo.

De acordo com a Organização para a Cooperação e Desenvolvimento Econômico (Organisation for Economic Cooperation and Development - OECD), a terceira missão das universidades no século 21 abrange todas as atividades relacionadas à geração e exploração de conhecimento e habilidades fora da academia (OECD, 2012; OECD, 2013). Consequentemente, gerar processos empreendedores é papel fundamental das universidades. É também de grande relevância relacionar universidade e sociedade em áreas como a transferência de tecnologia para o mundo dos negócios e para a sociedade em geral, formando empresários, promovendo empresas de tecnologia, incentivando iniciativas de interesse comunitário e oferecendo serviços especializados que respondam a verdadeiras necessidades sociais (OCDE, 2012; OECD, 2013).

No ensino de odontologia um novo perfil de professor também se faz necessário, pois as demandas dos estudantes estão em mudança. É imprescindível que o professor entenda o tempo e a sociedade na qual o discente está inserido, compreendendo seus valores, sua linguagem e a tecnologia que está sendo utilizada por eles, bem como o modo que isso contribui melhor para sua formação profissional, deixando de ser somente transmissor das técnicas odontológicas (Franco et al., 2009). Com isso, a formação dos docentes também entra em pauta de modo a suprir as necessidades atuais do curso de odontologia. Deve-se levar em conta a importância na forma com que o conteúdo é ministrado para os estudantes, o professor deve ser um facilitador na transmissão do conteúdo, permitindo ao aluno ser o centro de seu próprio conhecimento (Ferreira, Ferreira \& Freire, 2013). Dessa forma, deve-se modificar a maneira de administração de conteúdos e práticas envolvendo a diversificação de locais de aulas e meios de transmissão (Delors, 2001 apud Ferreira; Ferreira; Freire, 2013). Em consonância a isso, o estudante deve priorizar uma consciência crítica acerca da profissão e do mercado de trabalho, adotando uma postura ética e trabalho sustentável na Odontologia e conciliando o conhecimento técnico (Ferreira, \& Freire, 2013).

\section{Ensino-aprendizagem}

$\mathrm{O}$ processo de ensino-aprendizagem na área da saúde atualmente engloba os conceitos da "aprendizagem significativa" e "aprendizagem ativa" (Freitas et al., 2009). A aprendizagem significativa associa os conhecimentos prévios adquiridos na vivência do estudante. Já na aprendizagem ativa o estudante tem papel ativo na busca e produção do conhecimento e de novos sentidos, sendo o professor o facilitador do processo educacional (Feuerwerker et al., 2006).

Os métodos tradicionais são considerados ultrapassados muitas vezes. Isso porque não incentivam a criatividade dos discentes e sua capacidade associativa (Haguenauer, 2005). Com a evolução da tecnologia, ocorreram transformações na aquisição do conhecimento o qual se tornou mais rápido e dinâmico e mudanças no ensino odontológico têm sido propostas com o objetivo de capacitar o futuro profissional a promover a saúde e o bem-estar da população (De-Carli et al., 2019).

A visão de uma odontologia descontextualizada da realidade é apontada como um dos empecilhos que os profissionais formados em odontologia encontram no mercado de trabalho, pois, apesar de o curso proporcionar uma formação técnica adequada, a visão crítica e de mercado de trabalho ainda é prejudicada (Gontijo el al., 2020). Isso se deve pela falta do ensino de empreendedorismo no curso de odontologia já que os estudantes quando ingressam no mercado de trabalho, na grande maioria das vezes, não possuem conhecimentos de gestão e administração de carreira e consultórios odontológicos (Kirby, 2007). Por isso, é apontado que a ampliação de cenários de aprendizagem pelo aprimoramento desses conhecimentos é fundamental para formação de profissionais mais qualificados, inserindo na academia e a integração de conteúdos/disciplinas e implantação de práticas interdisciplinares aos alunos que abordem o tema (Diomede et al., 2020). 


\section{Metodologia}

$\mathrm{O}$ artigo se trata de um relato de experiência fundamentado na metodologia ativa da Aprendizagem Baseada em Projetos (ABP) de Bender (2015). A ABP possibilita o trabalho em equipe, o estímulo da criticidade, a autonomia e o exercício da criatividade (Bacich \& Moran, 2018). Isso acontece por meio da busca da solução de problemas em contextos relacionados ao cotidiano dos estudantes, ou seja, contextos fora da sala de aula.

Dessa forma, os projetos acadêmicos podem envolver ações interdisciplinares capazes de se aproximarem da realidade social de cada aluno, fazendo com que se apropriem do objeto de estudo e apliquem o conhecimento adquirido (Bender, 2015). Assim, o projeto de ensino permite a reflexão, o feedback, $a$ autoavaliação e a avaliação de pares e discussão com grupos para qualificar as ideias geradas. Em um projeto de aprendizagem é priorizado a geração de um produto, o qual pode ser uma ideia, uma iniciativa ou um bem físico (Pasqualetto, Veit \& Araujo, 2017). Essa metodologia é empregada para que o aluno consiga aplicar seus conhecimentos em alguma ação e desenvolver assim suas habilidades e competências. A aprendizagem colaborativa é um dos princípios dessa metodologia que se baseia no trabalho coletivo (Bacich \& Moran, 2018). Com isso os alunos identificam problemas existentes em algum nicho ou área de interesse e trazem soluções criativas para esses problemas.

Nesse sentido, o projeto consistiu em doze encontros que ocorreram quinzenalmente os quais foram embasados metodologicamente de acordo com o relato de Felippe e colaboradores (2020). Os minicursos foram realizados no auditório do Programa de Pós Graduação em Odontologia (PPGO), na Faculdade de Odontologia da UFPel. Cada encontro teve duração aproximada de uma hora e trinta minutos. A divulgação foi principalmente por meio da Internet, sendo criado eventos em redes sociais e fixação de cartazes em instituições parceiras como no Pelotas Parque Tecnológico, gerenciado pela Prefeitura de Pelotas, na incubadora de base tecnológica da UFPel, Conectar, e no Serviço Brasileiro de Apoio às Micro e Pequenas Empresas (SEBRAE/RS). Os palestrantes convidados estavam relacionados a esse ecossistema. As ações foram planejadas por uma equipe que compreendeu um bolsista de ensino, colaboradores e o coordenador do projeto.

\section{Relato de Experiência}

Foram abordados nos encontros quatro pilares de abordagem, sendo eles: "Experiências empreendedoras", "Inovação tecnológica", "Planejamento de modelo de negócios" e "Informação e atualização em empreendedorismo". Esses pilares foram eleitos pela equipe do projeto de acordo com o cronograma de palestras que foi montado. Foi possível identificar palestrantes aptos para desenvolver cada tema. Dentre os palestrantes estavam inclusos empresários locais, docentes de universidades e gestores de startups. Na Tabela 1 é possível visualizar a relação dos títulos dos encontros e palestrantes. 
Tabela 1 Relação dos minicursos realizados pelo projeto levando em conta a data, título do encontro, palestrante e pilar em que foi inserido.

\begin{tabular}{|c|c|c|c|}
\hline & \multicolumn{3}{|c|}{ Relação de encontros realizados } \\
\hline Data & Minicurso & Palestrante & Pilar \\
\hline $14 / 06 / 2018$ & $\begin{array}{l}\text { "Minha história } \\
\text { empreendedora" }\end{array}$ & $\begin{array}{c}\text { CEO de uma startup de agenciamento de } \\
\text { diaristas }\end{array}$ & "Experièncias empreendedoras" \\
\hline $28 / 06 / 2018$ & $\begin{array}{l}\text { "Como a ciència e a análise } \\
\text { de dados podem auxiliar na } \\
\text { tomada de decisōes?" }\end{array}$ & $\begin{array}{c}\text { CEO de uma startup de engenharia da } \\
\text { computação }\end{array}$ & $\begin{array}{l}\text { "Informação e atualização em } \\
\text { empreendedorismo" }\end{array}$ \\
\hline $12 / 07 / 2018$ & $\begin{array}{l}\text { "Nanotecnologia, impressào } \\
\text { 3D e outras inovaçōes em } \\
\text { biomateriais" }\end{array}$ & CEO da empresa Yller Biomateriais & "Inovaçào tecnológica" \\
\hline $26 / 07 / 2018$ & $\begin{array}{l}\text { "Desenvolvendo negócios: } \\
\text { incubaçào de empresas" }\end{array}$ & $\begin{array}{c}\text { Presidente da incubadora de base } \\
\text { tecnológica, conectar }\end{array}$ & "Experièncias empreenderas" \\
\hline $09 / 08 / 2018$ & "Odontologia Digital" & CEO de um centro de odontologia digital & "Inovação tecnológica" \\
\hline $23 / 08 / 2018$ & "Novos modelos de gestảo" & $\begin{array}{l}\text { Coordenadora do curso de MBA em } \\
\text { Gestão estratégica de negócios da UFPel }\end{array}$ & "Planejamento de modelo de negócios" \\
\hline $06 / 09 / 2018$ & $\begin{array}{l}\text { "Novos modelos de } \\
\text { empresas de saúde" }\end{array}$ & $\begin{array}{l}\text { CEO de uma startup de agendamentos de } \\
\text { consultas e presidente de uma } \\
\text { desenvolvedora de artigos hospitalares }\end{array}$ & $\begin{array}{l}\text { "Informação e atualização em } \\
\text { empreendedorismo" }\end{array}$ \\
\hline $06 / 12 / 2018$ & $\begin{array}{l}\text { "Empresas juniores, o que } \\
\text { sảo? }\end{array}$ & Presidente do conselho de EJs da UFPel & $\begin{array}{l}\text { "Informação e atualização em } \\
\text { empreendedorismo" }\end{array}$ \\
\hline $23 / 05 / 2019$ & $\begin{array}{l}\text { "Beneficios da interação } \\
\text { entre universidade e } \\
\text { empresas" }\end{array}$ & Consultora comercial & $\begin{array}{l}\text { "Informaçåo e atualização em } \\
\text { empreendedorismo" }\end{array}$ \\
\hline $06 / 06 / 2019$ & $\begin{array}{l}\text { "Como estruturar um } \\
\text { modelo de negócios com o } \\
\text { Camvas?" }\end{array}$ & $\begin{array}{c}\text { Professora do curso de administraçào da } \\
\text { UFPel }\end{array}$ & "Planejamento de modelo de negócios" \\
\hline $04 / 07 / 2019$ & $\begin{array}{l}\text { "Tendências de serviços em } \\
\text { atendimento à saúde" }\end{array}$ & $\begin{array}{l}\text { CEO de uma startup de agendamento de } \\
\text { consultas }\end{array}$ & $\begin{array}{l}\text { "Informação e atualizaçào em } \\
\text { empreendedorismo" }\end{array}$ \\
\hline $18 / 07 / 2019$ & "Startups B2B" & Fundadores de uma startup de tecnologia & $\begin{array}{l}\text { "Informação e atualização em } \\
\text { empreendedorismo" }\end{array}$ \\
\hline
\end{tabular}

Fonte: Autores.

O projeto teve duração de 11 meses, acontecendo de maio de 2018 até março de 2019. Os encontros foram realizados quinzenalmente, sendo que, em alguns momentos, houve intervalos maiores entre as reuniões por estas atividades terem que estar de acordo com o calendário da instituição de ensino superior. Foram utilizados materiais audiovisuais (PowerPoint) para as explanações dos palestrantes nos minicursos. As inscrições para a ação foram realizadas através de um e-mail e uma chamada era impressa antes do encontro para que fossem comprovadas as presenças. Os minicursos eram iniciados primeiramente com a apresentação do conteúdo pelos palestrantes, levando cerca de uma hora e depois eram realizadas as explanações sobre o assunto com perguntas da plateia e discussão entre os inscritos e os palestrantes nos 30 minutos finais. Na Figura 1 é possível visualizar os cartazes de divulgação de cada minicurso. 
Figura 1 Relação dos cartazes de divulgação dos minicursos.

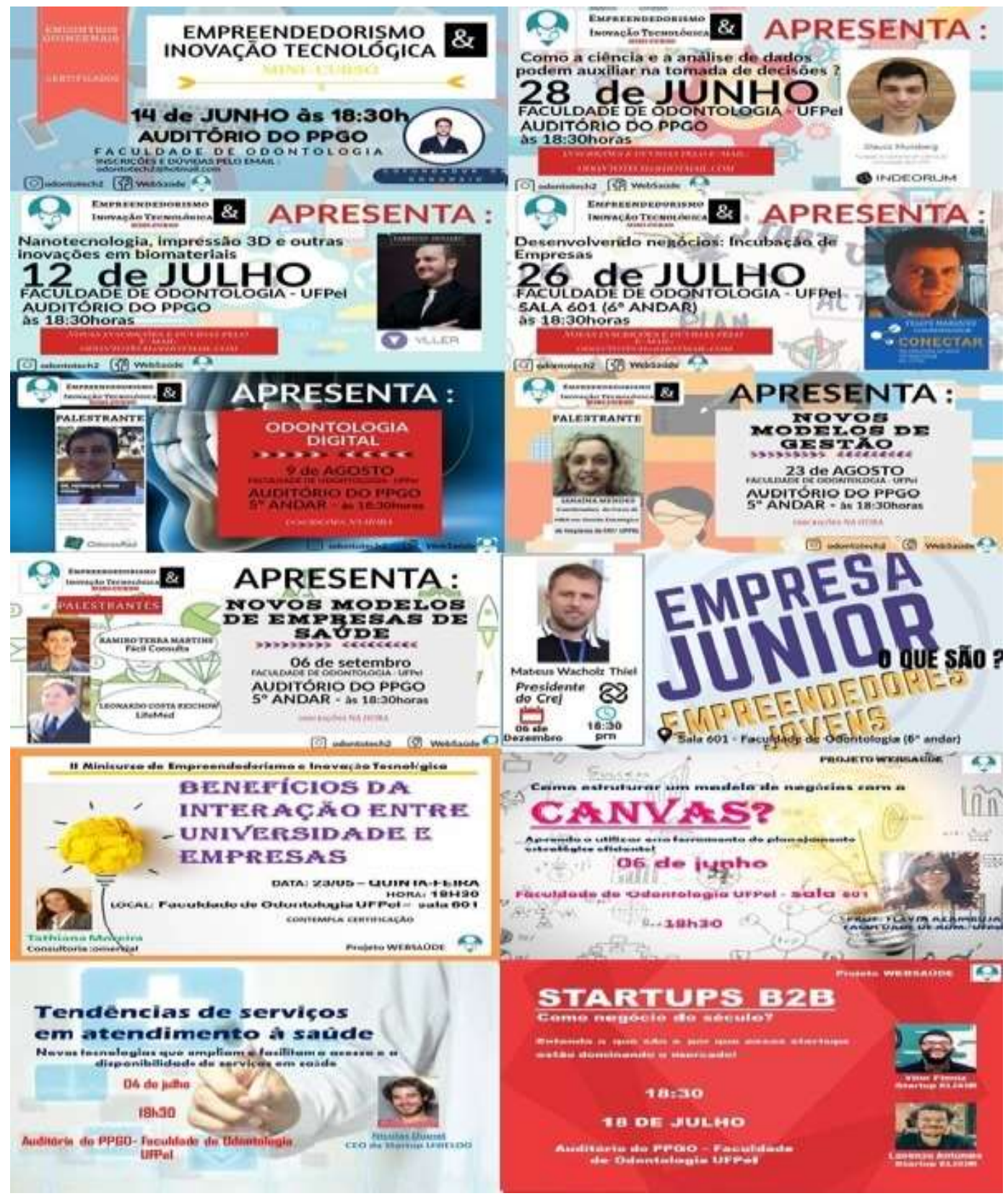

Fonte: Autores.

O pilar que abordou a experiência empreendedora dos palestrantes buscou exemplificar casos de sucesso, destacando características, ações e iniciativas que um empreendedor deve ter (ou desenvolver) para obter êxito no mundo dos negócios. Nos encontros sobre "Inovação tecnológica" também foi abordado pelos palestrantes temas que incluíam: odontologia digital, impressão 3D, nanotecnologia e o uso da ciência de dados para melhorar o desempenho de ações empresariais.

Já o pilar de "Planejamento de modelo de negócios" buscou elucidar de forma didática os principais itens que devem ser observados em um negócio, além de propor para os alunos atividades práticas por meio da ferramenta Canvas de planejamento estratégico. As palestras enquadradas como "Informação e atualização em empreendedorismo" buscaram explorar novos conhecimentos sobre esse ecossistema tendo como intuito atualizar os participantes sobre novas práticas e conceitos. Os conceitos de startups 2B2 e Empresas Juniores foram abordados, bem como a discussão sobre novos modelos de 
empresas de saúde, a interação entre universidades e o setor privado, e as tendências em serviços no atendimento à saúde. A Figura 2 ilustra um dos encontros realizados.

Figura 2 Minicurso sobre a tomada de decisões utilizando a ciência e a análise de dados.

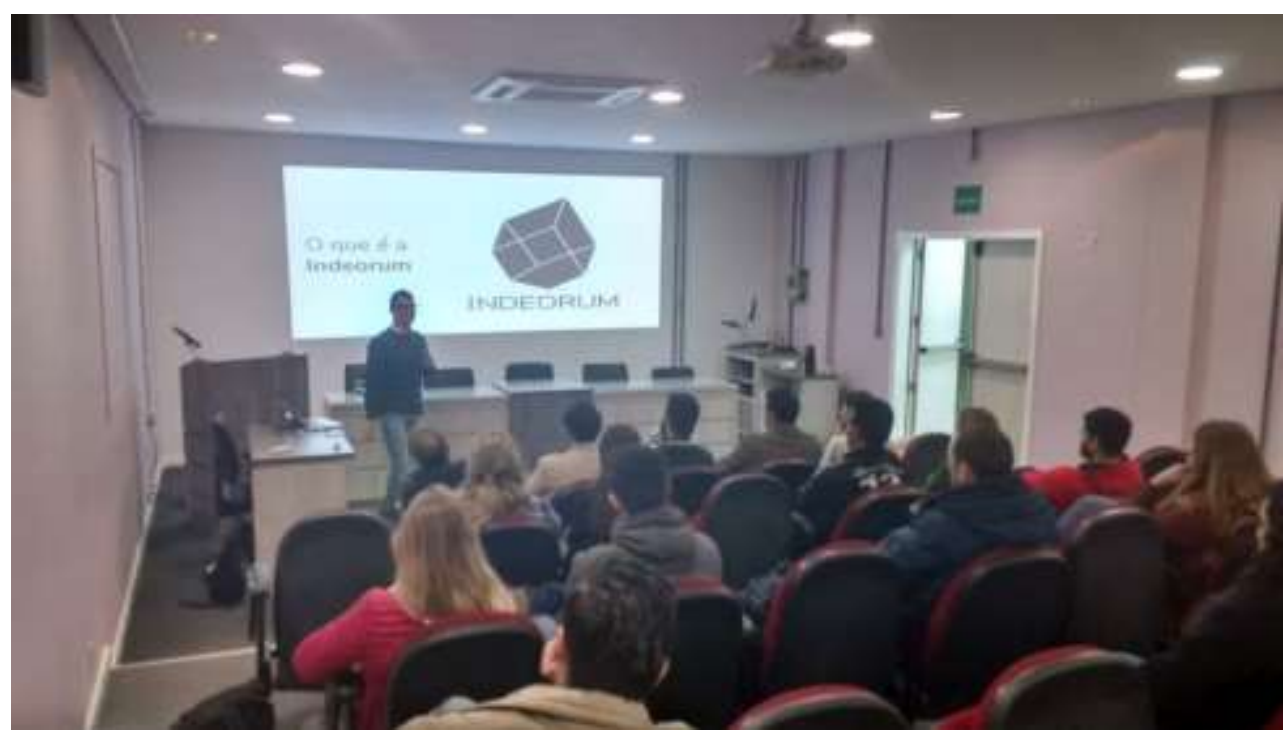

Fonte: Autores.

Os minicursos de Empreendedorismo e Inovação Tecnológica idealizados pelo projeto OdontoTech tiveram como objetivo introduzir os conhecimentos acerca do ecossistema de inovação tecnológica e empreendedorismo aos alunos do curso de graduação em odontologia da universidade. Sendo que a inovação tecnológica pode ser entendida como "uma fonte geradora de mudanças da atualidade, podendo ser uma nova ideia, um evento técnico descontínuo, que, após certo período de tempo, é desenvolvido até o momento em que se torna prático e, então, usado com sucesso" (Reis, 2004, p.42).

Além disso, é atividade das universidades a transferência de tecnologia e desenvolvimento de propriedade intelectual, bem como, a incubação de empresas, colaborando, assim, com a função empreendedora dessas instituições e com o desenvolvimento econômico-social da região em que estão inseridas (de Oliveira et al., 2021).

Nesse sentido, no contexto atual, devido à doença causada pelo coronavírus, a COVID-19, esse projeto poderia ser retomado de diferentes formas. A Sala de Aula Invertida, é uma delas, sendo uma estratégia de ensino e aprendizagem alternativa (da Silva et al., 2021). Nela no primeiro momento, o aluno utiliza o formato virtual para realizar um estudo prévio e depois esse assunto é discutido com o restante do grupo em sala de aula. Assim, o projeto otimizaria o tempo de contato entre os participantes, além de conferir iniciativa e autonomia aos alunos. O uso de Metodologias Ativas foi abordado no artigo de da Silva Feitosa e Valente (2021) e apontam para os possíveis benefícios dessa estratégia como o estabelecimento de um processo interativo de conhecimento, análise do panorama geral do assunto abordado e tomada de decisão com o objetivo de solucionar o problema apresentado.

Este projeto de ensino teve um significado muito importante como atividade complementar de empreendedorismo e inovação para os cursos de graduação da universidade como um todo, visto que o público ouvinte que participou não se restringiu aos estudantes de odontologia. Houve a participação de estudantes de graduação de outros cursos que tomavam conhecimento das atividades do projeto, incluindo a presença de alunos dos cursos de Agronomia, Administração, Ciências da Computação, Letras, Engenharia de Materiais e Farmácia, registrados nas listas de presença dos encontros. O indicador do impacto desse projeto em diferentes cursos universitários pôde ser evidenciado na adesão dos participantes, através das listas 
de presenças obtidas durante cada encontro quinzenal. Com as ações deste projeto, observou-se um maior surgimento de iniciativas para constituição de empresas juniores e atividades empreendedoras na universidade como um todo desencadeadas por diferentes cursos que se envolviam voluntariamente neste projeto. Com o Minicurso foi atingido um público de cerca de duzentos discentes de graduação e pós-graduação de diferentes cursos da universidade. Ao final do projeto, houve emissão de certificado de participação aos alunos nos minicursos ministrados.

\section{Considerações Finais}

O projeto OdontoTech por meio dos minicursos de Empreendedorismo e Inovação Tecnológica contribuiu para a formação dos discentes de maneira a complementar os conhecimentos sobre empreendedorismo e inovação, os quais são deficitários em alguns cursos, incluindo nas grades curriculares (ou projetos pedagógicos) dos cursos de odontologia. Além disso, promoveu a aproximação entre o ambiente acadêmico e os profissionais que já atuam no mercado, favorecendo, assim, a troca de experiências e vivências com profissionais que já estão no mercado e, consequentemente, uma melhor orientação dos alunos para a inserção no mercado de trabalho atual.

As atividades realizadas pelo projeto tentaram reunir bases teóricas que qualificassem a prática. Ademais representam um cenário inovador de ensino e aprendizagem com aspectos positivos para o conhecimento do mercado de trabalho e da inovação tecnológica em saúde. Por meio do presente relato é possível inferir que a promoção da educação empreendedora é uma estratégia eficaz para o fomento dos alunos a prática empreendedora e inovadora em suas áreas de atuação profissional. Além disso, é capaz de incentivar o desenvolvimento de capacidades técnicas (conhecimentos e habilidades), beneficiar a comunicação, trabalho em equipe e autoconfiança na formação de um profissional mais qualificado.

A mudança da cultura de ensino e aprendizagem centrada no professor para uma na qual o aluno esteja no centro e seja capaz de solucionar e identificar problemas é um desafio. A Lei de Diretrizes e Bases da Educação Nacional e as atuais diretrizes curriculares dos cursos de graduação da área de Saúde no Brasil evidenciam a necessidade de revisão dos métodos de ensino tradicionais e da incorporação do ensino de empreendedorismo e inovação em suas grades horárias. Isso porque o profissional formado pelo ensino superior deve ter pensamento crítico e espírito reflexivo, sendo proporcionado principalmente por meio de ensino por métodos ativos destacando-se do profissional orientado somente pelo método tradicional.

Dessa forma, compete as instituições de ensino superior estimular os discentes a refletirem quanto aos objetivos da aprendizagem e a importância de inserir o ensino do empreendedorismo e da inovação tecnológica na formação acadêmica, além de promover a capacitação e atualização dos docentes.

A partir desse relato, há um fomento para a implementação de novos projetos e metodologias de ensino no ambiente acadêmico de maneira a enriquecer e contribuir para o processo de ensino o qual passa por grandes modificações especialmente no âmbito da educação no ambiente virtual.

\section{Referências}

Bacich, L., \& Moran, J. (2018). Metodologias ativas para uma educação inovadora: uma abordagem teórico-prática. Penso Editora.

Bender, W. N. (2015). Aprendizagem baseada em projetos: educação diferenciada para o século XXI. Penso Editora.

Brasil. (2004). Lei n. 10.973, de 2 de dez. de 2004. Dispõe sobre incentivos à inovação e à pesquisa científica e tecnológica no ambiente produtivo e dá outras providências. Diário Oficial da República Federativa do Brasil, DF.

Brasil. (2001). Diretrizes Curriculares Nacionais dos Cursos de Graduação em Farmácia e Odontologia. http://portal.mec.gov.br/escola-de-gestores-daeducacao-basica/323-secretarias-112877938/orgaos-vinculados-82187207/12991-diretrizes-curriculares-cursos-de-graduacao

Carmona, V. C., Martens, C. D. P., \& de Freitas, H. M. R. (2020). Os antecedentes da orientação empreendedora em negócios sociais. Revista de Empreendedorismo e Gestão de Pequenas Empresas, 9(2), 71-96. 
da Silva, E.L., dos Santos, D.C.M., de Lima, A.C.B., e de Almeida, S.L. (2021). Sala de aula invertida no ensino superior de saúde: uma revisão sistemática. Research, Society and Development, 10 (14), e434101422083-e434101422083.

da Silva Feitosa, F.E., \& Valente, A.A.P. (2021). Metodologias ativas: uma inovação que pode virar modismo. Research, Society and Development, 10 (14), e330101422046-e330101422046.

De-Carli, A. D., Silva, A. D. D. M., Zafalon, E. J., Mitre, S. M., Pereira, P. Z., Bomfim, R. A., \& Theobald, M. R. (2019). Integração ensino-serviçocomunidade, metodologias ativas e Sistema Único de Saúde: percepções de estudantes de Odontologia. Cadernos Saúde Coletiva, $27,476-483$.

Del Prette, A., \& Del Prette, Z. A. P. (2003). No contexto da travessia para o ambiente de trabalho: treinamento de habilidades sociais com universitários. Estudos de Psicologia (Natal), 8, 413-420.

de Oliveira, A. G. M., Melo, M. C. D. O. L., \& De Muylder, C. F. (2016). Educação empreendedora: O desenvolvimento do empreendedorismo e inovação social em instituições de ensino superior. Revista Administração em Diálogo-RAD, 18(1), 29-56.

de Oliveira, J. R., dos Santos, W. P. C., Ribeiro, N. M., de Freitas Jorge, E. M., \& Araujo, M. 1. V. (2021). Programa de ideias inovadoras do IFBA: proposição de melhorias baseada em critérios de avaliação. Cadernos de Prospecção, 14(1), 94.

de Oliveira Matos, E. M., Arreguy, I. M. S., Jamelli, S. R., de Souza, F. B., \& de Amorim Carvalho, E. J. (2019). Aprendizagem baseada em equipes no ensino odontológico: o que pensam os estudantes? Revista da ABENO, 19(4), 91-101.

Dickson, P.H., Solomon, G.T. \& Weaver, K.M. (2008). Seleção empresarial e sucesso: educação importa? Jornal de desenvolvimento de pequenas empresas e empresas.

Diomede, A. M., Pasquinelli, F., de Moraes, R. G. B., Pimentel, A. C., Sendyk, W. R., \& Roman-Torres, C. V. G. (2020). Empreendedorismo e gestão, qual o acesso do aluno de Odontologia a ferramentas administrativas? Research, Society and Development, 9(8), e304985801-e304985801.

Dionello, R., Langhi, C., \& Okano, M. T. (2020). Educação profissional para startups: uma reflexão sobre o impacto do desenvolvimento de competências empreendedoras para o amadurecimento do ecossistema de startups no brasil. South American Development Society Journal, 5(15), 456.

Drejer, A. (2000). Organisational learning and competence development. The learning organization.

Etzkowitz, H. (2013). Anatomia da universidade empresarial. Informação em ciências sociais, 52 (3), $486-511$.

Etzkowitz, H., \& Zhou, C. (2017). Hélice Tríplice: inovação e empreendedorismo universidade-indústria-governo. Estudos avançados, 31, 23 -48.

Felippe, R. M., da Rosa, P. R. D. R., Ouriques, C. S., Irfan, M., Conceição, L. D., \& Lund, R. G. (2020). Odontologia Legal e Forense na formação de estudantes de Odontologia: relato de experiência de projeto de ensino multidisciplinar. Revista da ABENO, 20(2), $111-118$.

Ferreira, N. D. P., Ferreira, A. D. P., \& Freire, M. D. C. M. (2013). Mercado de trabalho na Odontologia: contextualização e perspectivas. Revista de Odontologia da UNESP, 42, 304-309.

Feuerwerker, L. C. (2006). Por que a cooperação com o SUS é indispensável para os cursos universitários na área da saúde. Olho Mágico, $13(1), 32-8$.

Fragoso, R., Rocha-Junior, W., \& Xavier, A. (2020). Fatores determinantes da intenção empreendedora em estudantes universitários no Brasil e em Portugal. Journal of Small Business \& Entrepreneurship, 32 (1), 33-57.

Franco, L. L. M. M., Soares, É. F., Martorell, L. B., \& Marcelo, V. C. (2009). O professor do curso de odontologia: sua formação e os desafios frente às exigências atuais. Revista Profissão Docente, 9(20), 57-74.

Freire, V. M. V., \& de Carvalho, J. M. (2021). Propriedade Intelectual para Inovação: percepções e perspectivas em uma escola profissionalizante. Cadernos de Prospecção, 14(2), 414.

Freitas, V. D. P., Carvalho, R. B. D., Gomes, M. J., Figueiredo, M. C., \& Faustini-Silva, D. D. (2009). Mudança no processo ensino-aprendizagem nos cursos de graduação em odontologia com utilização de metodologias ativas de ensino e aprendizagem. RFO UPF, 163-167.

Gontijo, L. P. T., Herval, Á. M., Carcereri, D. L., \& de Freitas, S. F. T. (2020). Aceitabilidade das metodologias ativas de ensino-aprendizagem entre discentes de odontologia. Revista Ibero-Americana de Estudos em Educação, 2023-2048.

Haguenauer C. (2005). Metodologias e estratégias na educação à distância. Latec. http:// www.latec.ufrj.br/portfolio/at/4\%20EAD\%20metodologias.Pdf

Junior, M. C. L., \& de Souza Baddauy, L. (2021). Política de Inovação, Proteção do Conhecimento e Empreendedorismo: um estudo da relação entre a Universidade Estadual de Londrina e o setor produtivo. Cadernos de Prospecção, 14(2), 430.

Kimwolo, A. K, Saina, C. K., \& Cheserek, G. J (2012). Efeitos das habilidades de treinamento de crédito no desempenho de vendas entre mulheres empresárias no condado de Elgeiyo Marakwet, no Quênia. Journal of Emerging Trends in Economics and Management Sciences, 3 (6), $945-950$.

Kirby, D. A (2004). Educação para o empreendedorismo: as escolas de negócios podem enfrentar o desafio? Educação + treinamento.

Lackéus, M. (2016). Value creation as educational practice-Towards a new educational philosophy grounded in entrepreneurship? Chalmers Tekniska Hogskola.

Marcos, L. (2018). Metodologias ativas: o protagonismo acadêmico. Revista Eletrônica Estácio Saúde, 7(2), 1-2.

OECD. (2012). A Guiding Framework for Entrepreneurial Universities. Development Centre Studies, OECDE Publishing. 
Research, Society and Development, v. 10, n. 15, e413101522748, 2021

(CC BY 4.0) | ISSN 2525-3409 | DOI: http://dx.doi.org/10.33448/rsd-v10i15.22748

OECD. (2013). Start-up Latin America: Promoting Innovation in the Region. Development Centre Studies, OECDE Publishing.

Pasqualetto, T. I., Veit, E. A., \& Araujo, I. S. (2017). Aprendizagem baseada em projetos no Ensino de Física: uma revisão da literatura. Revista Brasileira de Pesquisa em Educação em Ciências, 551-577.

Portal institucional UFPel. (2018). Projeto de ensino Odonto Tech. https://institucional.ufpel.edu.br/projetos/id/e2200.

Prastyaningtyas, E. W, Soetjipto, B. E, \& Rudijanto, E. T. D. (2020). O efeito da educação empreendedora e da personalidade na intenção empreendedora por meio da autoeficácia. Management and Economics Journal, 3 (3), 245-254.

Reis, D. R. (2004). Gestão da Inovação tecnológica. Manole.

Saraiva, L. A. S. (2007). O túnel no fim da luz: a educação superior em administração no Brasil e a questão da emancipação. Anais do Encontro Anual da Associação Nacional de Pós-Graduação e Pesquisa em Administração.

Uliana, B. M. (2015). As habilidades e competências empreendedoras para uma gestão de sucesso na Odontologia. Trabalho de Conclusão de Curso. Universidade Federal de Santa Catarina. Curso de Graduação em Odontologia. 